\title{
Ecologia e Mobilização Social: um Desafio para a Psicologia*
}

\author{
Paulo Roberto de Carvalho ${ }^{1}$ \\ ${ }^{1}$ Universidade Estadual de Londrina, PR, Brasil.
}

\author{
Sonia Regina Vargas Mansano ${ }^{2}$ \\ ${ }^{2}$ Universidade Estadual de Londrina, PR, Brasil.
}

Diversos foram os documentos elaborados por ocasião das conferências nacionais e internacionais sobre o meio ambiente. Parte desses documentos serviu como referência para que nações elaborassem políticas públicas de proteção e fiscalização ambiental. Entretanto, os resultados dessa produção documental ainda deixam muito a desejar diante dos índices que medem o avanço predatório de exploração da natureza em escala mundial. O objetivo do presente estudo teórico e documental consiste em analisar documentos elaborados em conferências internacionais sobre meio ambiente e seus desdobramentos na vida das cidades, com enfoque na problemática da subjetividade e, mais especificamente, do desejo. Na parte teórica, investiga-se a noção de sustentabilidade, mostrando que a preocupação com a natureza envolve as relações entre a população e as cidades. Na parte documental, são analisados fragmentos do documento chamado Agenda 21 no que se refere especificamente à conexão entre sustentabilidade, espaço urbano e mobilização social. Como resultado, constata-se o quanto as cidades estão diante do desafio de construir modos de vida sustentáveis que tem seu maior diferencial nas relações sociais e afetivas. Portanto, a mobilização coletiva e desejante das populações voltada para a preservação ecológica converte-se em um desafio a ser enfrentado também pela Psicologia.

Palavras-chave: Agenda 21. Sustentabilidade. Espaço urbano. Subjetividade. Psicologia.

\section{Ecology and Social Mobilization: a Challenge for Psychology}

\begin{abstract}
Several are the documents prepared on the occasion of national and international conferences on the environment. Part of these documents serves as a reference for Nations to draw up public policies for environmental protection and monitoring. However, the results of documentary production still leave much to be desired on the contents about the predatory nature of the advance on a global scale. The theoretical and documentary objective of the present study is to analyze the documents prepared at international conferences on environment and their consequences in the life of cities, focusing on problems of subjectivity and, more specifically, of desire. The theoretical part investigates the notion of sustainability, showing that the concern with nature involves relations between the population and the ways of life generated in the cities. In the part that deals with documents analysis, fragments of the Agenda 21 are analyzed as it relates specifically to the connection between sustainability, urban space and social mobilization. As a result, we see how the cities face the challenge of building sustainable lifestyles that have as a differential greater social and affective relations. Therefore, collective mobilization for populations with the desired ecological preservation becomes a challenge to be faced also by Psychology.
\end{abstract}

Keywords: Agenda 21. Sustainability. Urban space. Subjectivity. Psychology.

* Esta pesquisa recebeu suporte financeiro da Fundação Araucária de Apoio ao Desenvolvimento Científico e Tecnológico do Estado do Paraná. 


\title{
Ecología y la Movilización Social: un Desafío para la Psicología
}

\begin{abstract}
Resumen: Se prepararon varios documentos en conferencias nacionales e internacionales sobre el medio ambiente. Parte de estos documentos sirvió como referencia para que las naciones desarrollen políticas públicas para la protección y el cumplimiento del medio ambiente. Sin embargo, los resultados de esta producción documental aún dejan mucho que desear dados los índices que miden el avance depredador de la exploración de la naturaleza a escala mundial. El objetivo de este estudio teórico y documental es analizar documentos preparados en conferencias internacionales sobre el medio ambiente y sus consecuencias en la vida de las ciudades, centrándose en la subjetividad y, más específicamente, en el problema del deseo. En la parte teórica, se investiga la noción de sostenibilidad, lo que demuestra que la preocupación por la naturaleza involucra las relaciones entre la población y las ciudades. En la parte teórica, se investiga la noción de sostenibilidad, lo que demuestra que la preocupación por la naturaleza involucra las relaciones entre la población y las ciudades. En la parte documental, fragmentos del documento llamado Agenda 21 se analizan específicamente con respecto a la conexión entre sostenibilidad, espacio urbano y movilización social. Como resultado, podemos ver cuánto enfrentan las ciudades el desafío de construir estilos de vida sostenibles que tengan su mayor diferencial en las relaciones sociales y afectivas. Por lo tanto, la movilización colectiva y deseosa de las poblaciones enfocadas en la preservación ecológica se convierte en un desafío que la Psicología también debe enfrentar.
\end{abstract}

Palabras clave: Agenda 21. Sostenibilidad. Espacio urbano. Subjetividad. Psicología.

\section{Introdução}

No decorrer das últimas décadas, a preocupação com a preservação da natureza atravessou fronteiras e ganhou relevância global. Com isso, os impasses gerados pela exploração predatória do meio ambiente começaram a ser debatidos em diversos âmbitos das sociedades, envolvendo os segmentos governamentais, as organizações públicas e privadas, as instituições de pesquisa e ensino, bem como a população. Nessa direção, ocorreu uma série de conferências de âmbito nacional e internacional sobre meio ambiente que, a partir de diferentes perspectivas, colocaram em evidência a problemática ambiental ora instalada e elaboraram diferentes documentos utilizados como norteadores para efetivação de políticas públicas de combate à destruição da natureza.

Os documentos possuem relevância e impacto social, na medida em que são tomados como referência para elaboração de políticas de proteção ambiental, assim como são base para elaboração de dispositivos de controle sobre a depredação sistemática da natureza. Diante dos resultados limitados obtidos a partir da implementação das políticas e procedimentos que se originaram de tais conferên- cias e documentos, entretanto, tornou-se relevante dar visibilidade à insustentabilidade que ora vivemos em relação à vida urbana e aos problemas ambientais nela emergentes. Tal situação demanda uma análise social sobre a distância cada vez maior entre a existência que temos e aquela que desejamos no âmbito das cidades. A perspectiva teórica aqui adotada reúne autores como Guattari (1992, 1997; Guattari, \& Rolnik 1996), Godoy (2008) e Stengers (2015), tendo como norteadora as noções de subjetividade e desejo. Cabe considerar que uma problematização desse tipo depende do estranhamento, da insatisfação para com a existência que temos atualmente, fundada na tolerância para com a produção de lixo e na exploração sistemática da natureza. Estudos recentes (Burton, 2015; Castro, 2015; Massumi, 2017), empreendidos por diferentes áreas de conhecimento, demonstram não apenas a relevância do tema como também a urgência em o debater nos mais variados âmbitos. Desse modo, o presente estudo justifica-se pela necessidade aprofundar a investigação sobre a articulação entre sustentabilidade e espaço urbano. Sua contribuição está em dar visibilidade às implicações sociais desse problema no que se refere especificamente à interface entre desejo e política. 
Acreditamos que a Psicologia Social, como área de conhecimento que adota uma abordagem crítica e política para compreender os problemas emergentes no cotidiano, possui aparato conceitual e metodológico pertinente para contribuir com essa discussão, buscando analisar as possibilidades e limites políticos para consolidar uma sustentabilidade efetiva no espaço urbano.

\section{Considerações metodológicas}

O trajeto metodológico construído para esta pesquisa envolveu dois momentos: teórico e empírico. A parte teórica foi organizada da seguinte maneira: primeiro, foi realizada uma investigação histórica acerca das conferências e debates internacionais sobre o meio ambiente, atribuindo especial atenção à noção de sustentabilidade e seus desdobramentos políticos (Meadows, Meadows, Randers, \& Behrens, 1972; Veiga, 2013; Vizeu, Meneghetti, \& Seifert, 2012; Misoczky, \& Böhm, 2012). Em seguida, efetuou-se uma análise sobre o desenvolvimento do espaço urbano e a problemática dos modos de vida engendrados no cotidiano das cidades, recorrendo, principalmente, aos estudos de Santos (2000), Rolnik (2013), Bertini (2014), Harvey (2013a) e Malheiros, Phlippi e Coutinho (2008). Localizados em áreas distintas do conhecimento, cada um desses autores demonstra, a seu eu modo, o quanto a expansão das cidades e o aumento demográfico tornaram-se um problema complexo a ser enfrentado pela população e pelos governantes.

$\mathrm{Na}$ parte empírica, foi realizada uma análise documental, por meio da qual se buscou identificar e compreender como a sustentabilidade e o espaço urbano são mencionados na denominada Agenda 21 (Brasil, 2016b). Esta é considerada um dos principais documentos elaborado por ocasião da Conferência das Nações Unidas sobre o Meio Ambiente e o Desenvolvimento (CNUMAD), também conhecida como "Rio-92", ocorrida na cidade do Rio de Janeiro, em 1992. O documento, em sua forma geral, é composto por um preâmbulo, quatro seções (1. Dimensões sociais e econômicas; 2. Conservação e gestão dos recursos para o desenvolvimento; 3. Fortalecimento do papel dos grupos principais; 4. Meios de execução) e 41 capítulos distribuídos entre as quatro seções anteriormente elencadas. A peculiaridade da Agenda 21 é que ela foi desdobrada em outras duas possibilidades: Agenda 21 Nacional e Agenda 21 Local, com o objetivo de implicar os diferentes segmentos sociais em sua elaboração e execução.

A unidade de análise selecionada especificamente para esta investigação comportou três capítulos nos quais a mobilização social e a cidade são amplamente discutidas. São eles: capítulo 5 (Dinâmica Demográfica e Sustentabilidade), capítulo 7 (Promoção do Desenvolvimento Sustentável dos assentamentos humanos) e capítulo 8 (Integração entre meio ambiente e desenvolvimento na tomada de decisões). A partir desse recorte, procedeu-se uma busca de duas expressões: "cidade" e "participação social”. Esta escolha deveu-se ao fato de que os três capítulos abordam de maneira direta os problemas enfrentados na organização do espaço urbano e assinalam a relevância da participação social, do engajamento e do envolvimento coletivo no planejamento das cidades.

Os conceitos de subjetividade, desejo e política como produções sociais, tal qual compreendidos por Guattari (1992, 1997; Guattari, \& Rolnik, 1996), foram utilizados como principais ferramentas conceituais para realizar a análise dos fragmentos selecionados no documento de referência. Por fim, já nas considerações finais, foi realizado um diálogo entre os estudos teóricos e documentais, com vistas a identificar e questionar os limites e possibilidades enfrentados na discussão e execução da Agenda 21.

\section{A dimensão política das conferências internacionais e dos documentos gerados}

Uma das primeiras iniciativas que buscou debater os problemas efetivos do meio ambiente foi a denominada Conferência das Nações Unidas sobre o Meio Ambiente Humano, ocorrida no ano de 1972, em Estocolmo, na Suécia, organizada pela Organização das Nações Unidas (ONU). Naquela ocasião, que contou com a participação de diversos chefes de estado, a sustentabilidade foi definida como a capacidade que a humanidade possui para suprir suas necessidades, valendo-se das riquezas naturais, sem comprometer, entretanto, sua possibilidade de exploração por gerações futuras (Meadows et al., 1972). Após esta conferência, a problemática da relação entre o homem e a natureza passou a ser amplamente debatida em eventos internacionais sobre o meio ambiente, dentre as quais destacamos a "Conferência ECO 92”, realizada em 1992, na cidade do 
Rio de Janeiro; a "Rio + 10" ou "Cúpula Mundial sobre Desenvolvimento Sustentável”, realizada em 2002, na cidade de Johanesburgo - África do Sul; a "Rio + 20" ou "Conferência das Nações Unidas sobre Desenvolvimento Sustentável”, realizada em 2012, novamente na cidade do Rio de Janeiro; e mais recentemente, a Conferência do Clima da ONU (COP-21), realizada em 2015, na cidade de Paris.

A constatação mais incisiva que se pode extrair de uma abordagem sistemática da documentação produzida nas conferências é que não vivemos o tempo histórico no qual o Estado deverá ser abolido em função do livre trânsito de mercadorias e serviços em escala global. Ao contrário, trata-se de se redefinir o papel do Estado, aproximando-o das problemáticas estratégicas relacionadas ao meio ambiente. Nesse sentido, Sassen afirma:

Uma consequência importante dessa participação estratégica dos Estados nos processos globais é que, guiada por interesses diferentes, os Estados poderiam reorientar seus objetivos, afastando-se da agenda corporativa global e indo em direção a agendas globais sobre o meio ambiente, os direitos humanos, a justiça social e a mudança climática (2016, p. 139).

Essa abordagem crítica referente à relação dos Estados com o meio ambiente pode ser desdobrada em duas vertentes distintas, ainda que complementares: por um lado, intensificar a elaboração de documentos e acordos planetários que deem suporte para as transformações necessárias à manutenção da vida e, por outro, uma aproximação decisiva, em âmbito nacional e local, com o cotidiano das populações. E é nesse contexto que se pode reconhecer a importância estratégica da formulação e implementação das políticas públicas ambientais, revertendo o constrangimento continuado que a orientação neoliberal impõe às mesmas.

Em uma análise preliminar, foi possível perceber nos eventos anteriormente citados que, para além de uma iniciativa estatal de elaboração de políticas públicas regulatórias e fiscalizadoras voltadas ao meio ambiente, tais conferências deram visibilidade a uma preocupação crescente da sociedade global. Essa preocupação expressa a necessidade de fortalecer o debate sobre o futuro da natureza, da expansão da vida e da sociabilidade em nosso planeta (Harvey, 2013a). Cada uma dessas conferências gerou uma série de documentos, relatórios e acordos que, em alguma medida, orientaram a elaboração de políticas públicas que nortearam práticas de preservação nas nações envolvidas.

Os resultados dessas iniciativas, entretanto, ainda são bastante tímidos diante da gravidade da problemática ambiental instalada em nível mundial (Stengers, 2015). Autores que se dedicam a uma análise crítica sobre a sustentabilidade (Veiga, 2013; Vizeu et al., 2012; Misoczky, \& Böhm, 2012) evidenciam o quanto os termos e procedimentos técnicos utilizados para abordar a problemática do meio ambiente ainda são pouco fundamentados e amplamente determinados por interesses econômicos. Tais interesses, pelas mais diversas vias, se sobrepõem à busca de soluções efetivas que possam, ao menos, promover um amplo debate do problema.

A questão é agravada quando, aos olhos da população, aparecem separados os valores vigentes capitalistas (de acumulação a qualquer custo) da depredação sistemática do meio ambiente (pela produção e consumo). Com isso, torna-se difícil fazer com que o consumidor, por exemplo, reconheça sua implicação social e ecológica nos atos de consumir e descartar. Consumir torna-se, então, uma prática amplamente disseminada e compartilhada no social, o que intensifica a exploração dos recursos naturais e a produção descontrolada de resíduos urbanos, altamente poluentes. Tanto Stenger (2015) quanto Žižek (2017) veem nessa situação uma catástrofe que já está em curso, muitas vezes não identificada na ação dos sujeitos em suas vidas cotidianas. Diz Žižek:

catástrofe não é a autodestruição atômica da humanidade, mas a relação com a natureza que a reduz à sua exploração tecnocientífica. Catástrofe não é a nossa ruína ecológica, mas a perda de raízes domésticas que possibilita a implacável exploração da terra. Catástrofe não é sermos reduzidos a autômatos manipulados pela biogenética, mas a própria abordagem que torna possível essa expectativa (2017, p. 34-35).

Desse modo, é possível entrever uma série de campos potenciais de intervenção para a Psicologia Social. Abordar criticamente a relação do homem com a natureza seria o primeiro deles. Trata-se também de conhecer e intervir sobre o que o autor chama de pro- 
cessos de perda das raízes domésticas, revertendo a exploração predatória que se estende pelo planeta.

O que se nota, entretanto, é uma espécie de distanciamento subjetivo em relação aos resultados predatórios da produção e do consumo. Tal distanciamento cria as condições para que a exploração da natureza continue avançando, inviabilizando uma análise crítica efetiva sobre o que estamos ajudando a fazer com nossa vida, com a vida daqueles que nos cercam e, em especial, com o futuro do planeta. Apesar de as iniciativas internacionais de promover debates sobre a questão do meio ambiente terem acontecido de maneira regular desde o final do século XX, Misoczky e Böhm (2012, p. 556) assinalam: "O fato é que quase 20 anos e centenas de Conferências e Encontros depois da Eco-92, depois de milhares de páginas de resoluções, declarações e protocolos, a situação ambiental no planeta continua se deteriorando". Fica evidente, portanto, que sem adotar uma análise mais situada das implicações subjetivas, afetivas e políticas presentes nessa problemática, as ações de preservação do meio ambiente se defrontam com uma espécie de descaso e indiferença social.

\section{0 meio ambiente e as cidades}

Em 2000, Santos, juntamente de um grupo de geógrafos brasileiros, escreveu o chamado "O Papel ativo da geografia: um manifesto", no qual a questão dos territórios foi problematizada em sua vertente política. Neste manifesto, os autores definem o que chamam de "território usado" que, sob seu ponto de vista, "constitui-se como um todo complexo onde se tece uma trama de relações complementares e conflitantes. Daí o vigor do conceito, convidando a pensar processualmente as relações entre o lugar, a formação socioespecial e o mundo" (Santos, 2000, p. 3). O território urbano compreende, para os autores, uma multiplicidade de forças, sendo que muitas delas confrontam-se quando interesses individuais e/ou coletivos se manifestam.

Foi o que vimos acontecer, por exemplo, nas manifestações que tomaram as ruas das maiores cidades brasileiras no ano de 2013. Naquele momento, forças díspares eclodiram e ganharam espaço de expressão, mostrando à própria população e, principalmente aos governantes, que as cidades, por mais que estejam atravessadas pela impessoalidade e individualidade capitalistas, têm a potência de se manifestar e desejam fazê-lo. No prefácio de uma recente publicação sobre este acontecimento urbano, a urbanista Rolnik faz a seguinte consideração "a voz das ruas não é uníssona. Trata-se de um concerto dissonante, múltiplo, com elementos progressistas e de liberdade, mas também de conservadorismo e brutalidade, aliás, presentes na própria sociedade brasileira" (Rolnik, 2013, p. 3). Daí advém a dificuldade de acolhê-la e compreendê-la.

Buscando aproximar as noções de relações sociais urbanas e meio ambiente, o estudo de Veiga (2006) esclarece o quanto essa temática é desafiadora para o século XXI. Nele, temos a incumbência não apenas de preservar a natureza, mas também viabilizar a continuidade da vida humana, contando tanto com as facilidades tecnológicas e informacionais que conquistamos nas últimas décadas quanto com as debilidades relacionais que geramos em função desses mesmos avanços.

Nesse sentido, a vida nas cidades é alvo de diferentes intervenções que vão desde a gestão governamental até o modo como o cidadão comum, que habita os bairros e comunidades, se mobiliza para construir uma convivência possível com seus pares e com a natureza. Apesar das diversas discussões e conferências realizadas desde a segunda metade do século XX em âmbito nacional e internacional, a sustentabilidade (em sua tríade ambiental, econômica e social) é uma construção ainda abstrata e pouco precisa em sua dimensão social, que mostra seus limites na articulação entre natureza, socialização e espaço urbano. Na área da Psicologia Social, o estudo de Bertini (2014) dedica-se a fazer essa aproximação analítica entre espaço urbano e subjetividade, evidenciando a urgência de uma avaliação mais situada sobre o que estamos fazendo com a natureza e com as relações sociais neste tempo histórico.

É o que demonstra também o estudo de Paulista, Varvakis e Montibeller (2008, p. 188), quando os autores destacam: "A dimensão social, embora aproxime a dimensão humana da temática do desenvolvimento sustentável, é insuficiente, pois se restringe a aspectos externos à dinâmica de interação dos grupos sociais com o meio ambiente". Tal problemática, uma vez que nem sempre é reconhecida e assumida como sendo da esfera do coletivo, acaba sendo delegada a grupos específicos de ecologistas ativistas. Aí se situa a dificuldade de agregar condições mínimas para que seja debatida em um âmbito político e populacional. Nessa direção, o estudo de Sassen (2016) demonstra 
a gravidade do momento em que vivemos, no qual o sistema econômico revela-se cada vez mais devastador e predador tanto dos recursos naturais quanto das existências mais vulneráveis.

$\mathrm{O}$ que os autores acima citados denunciam ao assinalar que o debate se restringe a aspectos externos é a ausência da discussão sobre a subjetividade, por meio da qual a vida qualificada (não reduzida à mera sobrevivência) ganha concretude. De acordo com Guattari, cabe considerar que as "mentalidades coletivas mudam e mudarão amanhã cada vez mais rápido” (Guattari, 1992, p. 177). Nesse sentido, o autor acrescenta: "É preciso que a qualidade da produção dessa nova subjetividade se torne a finalidade primeira das atividades humanas e, por essa razão, ela exige que tecnologias apropriadas sejam postas a seu serviço" (Guattari, 1992, p. 177). Ora, quem estaria implicado com tal produção de maneira política e localizada? É aí que o autor conclui: "tal recentramento não é apenas tarefa de especialistas mas requer uma mobilização de todos os componentes da 'cidade subjetiva'” (Guattari, 1992, p. 177).

A conexão entre subjetividade, natureza e política urbana torna-se, nos estudos anteriormente citados, a condição de possibilidade para avançar na efetivação de uma sustentabilidade. Os obstáculos e limites emergentes nesse campo são notáveis. Isso pode ser constatado no estudo de índices realizado por Malheiros et al. (2008) que demonstra a dificuldade de operacionalização e acompanhamento da Agenda 21 no Brasil. Nele, os autores comparam os pontos elencados como prioridade da Agenda 21 brasileira com os Indicadores de Desenvolvimento Sustentável (IDS) gerados pelo Instituto Brasileiro de Geografia e Estatística (IBGE). Os autores concluem:

O Governo brasileiro não tem um sistema de monitoramento e avaliação da Agenda 21, cuja responsabilidade pelo acompanhamento de sua implementação é da Cides [Consórcio Público Intermunicipal de Desenvolvimento Sustentável], não havendo ainda estrutura própria de governo para o cumprimento de tão expressiva atribuição de interesse da sociedade e de administrações engajadas. Essa questão reforça a necessidade de se colocar esforços na integração das atividades de implementação e acompanhamento da Agenda 21 brasileira e dos indicadores IDS do IBGE (Malheiros et al., p. 18).
Sustentabilidade, subjetividade e cidades, portanto, são inseparáveis quando analisamos os modos de viver e se relacionar atualizados no contemporâneo. Por isso mesmo, acompanhamos Foucault sobre a necessidade de elaborar um "diagnóstico do presente" (Foucault, 2014, p. 34), sendo este ao mesmo tempo crítico e localizado. Um diagnóstico que "não procura mais dizer a verdade que possa valer para todos e para todos os tempos" (Foucault, 2014, p. 34), uma vez que sua função política consiste em acompanhar os movimentos, alianças e confrontos que um interesse coletivo tem potência para colocar em curso, bem como qual o investimento afetivo a ele destinado. É nesse sentido que a noção de desejo, tal qual concebida por Deleuze, pode ser aqui evocada. Para o autor, o desejo implica "um agenciamento determinado, um co-funcionamento" (p. 130). Na relação entre homem e natureza, são diversos os componentes desejantes que entram em cena, necessitando precisamente de serem agenciados por uma instância coletiva que seja produtora de sentido.

No que se refere especificamente ao meio ambiente, Stengers (2014) também colabora com a elaboração desse diagnóstico mostrando que os avanços da devastação nos aproximam de uma era de catástrofes e barbáries. Dar visibilidade e analisar criticamente o cenário contemporâneo das cidades envolve a experimentação de situações que são singulares e não generalizáveis. Assinala Stengers (2015, p. 127): "precisamos que as histórias afirmem sua pluralidade, pois não se trata de construir um modelo, e sim uma experiência prática". Se os limites são evidentes, cabe compreender como eles são expressos em um documento específico, a Agenda 21, e quais as possibilidades de superação dos mesmos para avançar na potencialização da existência comum e não na mera destruição da natureza. Uma direção a ser considerada é o envolvimento subjetivo e desejante das populações na problemática ambiental. Analisaremos estas possibilidades na próxima seção.

\section{Resultados e discussão: a Agenda $21 \mathrm{em}$ análise}

Na sequência, serão apresentados os dados coletados na Agenda 21, os quais foram analisados com base no referencial teórico adotado no decorrer do estudo. Primeiramente, selecionamos os fragmentos referentes à cidade, dando destaque ao seguinte enunciado: 
5.3. O crescimento da população mundial e da produção, associado a padrões não sustentáveis de consumo, aplica uma pressão cada vez mais intensa sobre as condições que tem nosso planeta de sustentar a vida. Esses processos interativos afetam o uso da terra, a água, o ar, a energia e outros recursos. As cidades em rápido crescimento, caso mal administradas, deparam-se com problemas ambientais gravíssimos. O aumento do número e da dimensão das cidades exige maior atenção para questões de Governo local e gerenciamento municipal. Os fatores humanos são elementos fundamentais a considerar nesse intricado conjunto de vínculos; eles devem ser adequadamente levados em consideração na formulação de políticas abrangentes para o desenvolvimento sustentável. Tais políticas devem atentar para os elos existentes entre as tendências e os fatores demográficos, a utilização dos recursos, a difusão de tecnologias adequadas e o desenvolvimento (Brasil, 2016b).

O espaço urbano e seu crescimento acentuado nas últimas décadas produzem grande impacto sobre a natureza e as relações sociais. Ao mesmo tempo, a gestão urbana ainda carece de políticas que acolham tal desenvolvimento em sua amplitude, reduzindo-se a realizar atividades paliativas que estão aquém dos problemas gerados pela explosão demográfica. Quando a Agenda 21 aborda essa temática, evidencia a urgência não apenas de intervenção imediata, mas também de elaboração de políticas públicas que favoreçam um planejamento do crescimento populacional e do espaço urbano. Tal como assinalado por Guattari (1992), um investimento na preservação do meio ambiente passa necessariamente por questões que são de ordem subjetiva, sendo que, sem considerar a vinculação da população com esse problema, as intervenções são praticamente inócuas.

$\mathrm{O}$ vínculo que os moradores das cidades estabelecem entre si ou ainda a vivência afetiva compartilhada por eles no espaço urbano será fundamental para que a ação coletiva se produza e se sustente. No limite, só será possível engendrar uma resposta à questão ambiental à medida que seja atribuído valor à vida, de si e dos outros. E isso nem sempre acontece, dado o conjunto extenso de adversidades que as populações experimentam em seu cotidiano. A perda da qualidade de vida, então, pode se reverter em mais isolamento e ausência de comprometimento com o coletivo, num processo de retroalimentação que precisa ser revertido. Daí a importância de uma intervenção em diferentes contextos. Essa dificuldade é abordada na Agenda 21 quando especifica:

5.4. Há a necessidade de desenvolver estratégias para mitigar tanto o impacto adverso das atividades humanas sobre o meio ambiente como o impacto adverso das mudanças ambientais sobre as populações humanas. Prevê-se que em 2020 a população mundial já tenha ultrapassado os 8 bilhões de habitantes (Brasil, 2016b).

Fica evidente que o crescimento populacional e a ampliação do território urbano configuram-se como os maiores desafios para engendrar um programa voltado à sustentabilidade. Será nesse contexto da ação cotidiana dos sujeitos e do estilo de vida que os mesmos adotam que a intervenção se mostra necessária. Mas, isso só é possível, mais uma vez, abordando as questões da subjetividade presente no meio urbano. Para Guattari (1992, p. 170) "o porvir da humanidade parece inseparável do devir urbano". Isso fica claro quando, na Agenda 21, comparece o seguinte fragmento:

5.16. De modo geral, os planos existentes de apoio ao desenvolvimento sustentável reconhecem tendências e fatores demográficos como elementos que exercem uma influência crítica sobre os padrões de consumo, a produção, os estilos de vida e a sustentabilidade a longo prazo. No futuro, porém, será necessário dedicar mais atenção a essas questões por ocasião da formulação da política geral e da elaboração dos planos de desenvolvimento. Para fazê-lo, todos os países terão de aperfeiçoar suas próprias condições de avaliar as implicações de suas tendências e fatores demográficos no que diz respeito a meio ambiente e desenvolvimento. Além disso, conforme apropriado, esses países também terão de formular e implementar políticas e programas de ação (Brasil, 2016b).

Uma das críticas que recai sobre a Agenda 21 é precisamente a maneira abstrata e generalista como ela menciona os problemas e suas possíveis soluções (Misoczky, \& Böhm, 2012). Isso dificulta uma prática 
efetiva de proposição e realização de políticas bem como o controle sobre as ações executadas. Quando analisamos tal crítica, fica explícita que a maior dificuldade enfrentada para colocar em prática os documentos e acordos assinados é a necessidade premente da participação do cidadão e do empenho dos governos em fazer valer os acordos. Adentramos, assim, na difícil abordagem da mobilização social, citada de maneira sistemática no capítulo 7 da Agenda 21, como é possível verificar no fragmento abaixo:

7.4. O objetivo geral dos assentamentos humanos é melhorar a qualidade social, econômica e ambiental dos assentamentos humanos e as condições de vida e de trabalho de todas as pessoas, em especial dos pobres de áreas urbanas e rurais. Essas melhorias deverão basear-se em atividades de cooperação técnica, na cooperação entre os setores público, privado e comunitário, e na participação, no processo de tomada de decisões, de grupos da comunidade e de grupos com interesses específicos, como mulheres, populações indígenas, idosos e deficientes. Tais abordagens devem constituir os princípios nucleares das estratégias nacionais para assentamentos humanos (Brasil, 2016b).

Em um tempo histórico marcado pela impessoalidade capitalista, no qual a subjetividade encontra-se investida na busca incessante por acúmulo material e aumento de renda, torna-se difícil implicar a população com temáticas que são de ordem coletiva e comunitária. O documento analisado aborda essa dificuldade, tendo em vista a incidência com que a participação social é invocada. Tal como é possível constatar no fragmento abaixo:

7.20. Todas as cidades, em especial as que se caracterizam por sérios problemas de desenvolvimento sustentável, devem, em conformidade com as leis, normas e regulamentos nacionais, desenvolver e fortalecer programas voltados para atacar esses mesmos problemas e direcionar seu desenvolvimento por um caminho sustentável [...]. As cidades individuais devem, quando apropriado:

(a) Institucionalizar uma abordagem participativa do desenvolvimento urbano sustentável, baseada num diálogo permanente entre os atores envolvidos no desenvolvimento urbano (o setor público, o setor privado e as comunidades), especialmente mulheres e populações indígenas;

(b) Melhorar o meio ambiente urbano promovendo a organização social e a consciência ambiental por meio da participação das comunidades locais na identificação dos serviços públicos necessários, do fornecimento de infra-estrutura urbana, da melhoria dos serviços públicos e da proteção e/ou reabilitação de antigos prédios, locais históricos e outros elementos culturais (Brasil, 2016b).

Listar as ações necessárias para preservar a natureza no espaço urbano consiste em apenas uma parte da intervenção. O maior problema encontrado está nas maneiras de promover e sustentar a implicação das populações com o processo. De acordo com Guattari (1997), isso passa necessariamente pela produção de subjetividades conectadas às questões ambientais, capazes de reconhecer o problema para além da esfera individual. No capítulo 8 do documento analisado, essa questão é discutida, mais uma vez, sob o enfoque da participação:

8.3. O objetivo geral é melhorar ou reestruturar o processo de tomada de decisões de modo a integrar plenamente a esse processo a consideração de questões sócio-econômicas e ambientais, garantindo, ao mesmo tempo, uma medida maior de participação do público. Reconhecendo que os países irão determinar suas próprias prioridades, em conformidade com suas situações, necessidades, planos, políticas e programas nacionais preponderantes, propõem-se os seguintes objetivos:

(a) Realizar um exame nacional das políticas, estratégias e planos econômicos, setoriais e ambientais, para efetivar uma integração gradual entre as questões de meio ambiente e desenvolvimento;

(b) Fortalecer as estruturas institucionais para permitir uma integração plena entre as questões relativas a meio ambiente e desenvolvimento, em todos os níveis do processo de tomada de decisões; 
(c) Criar ou melhorar mecanismos que facilitem a participação, em todos os níveis do processo de tomada de decisões, dos indivíduos, grupos e organizações interessados (Brasil, 2016b).

Desde o início do século XXI, notou-se um esforço, por parte do governo brasileiro, em criar condições mínimas para envolver a população com o debate sobre a vida urbana, incluindo aí os problemas relativos à preservação do meio ambiente. Um dos dispositivos para alcançar tal mobilização foi a criação, em 2001, do denominado "Estatuto das Cidades", cujo objetivo consiste em elaborar instrumentos que favoreçam o desenvolvimento organizado das cidades, tendo com principal protagonista a própria população - que é convocada a expressar suas opiniões, dificuldades e necessidades. Isso acontece em audiências públicas com foco na construção da gestão orçamentária participativa. Dois anos depois, em 2003, foi criado o Ministério das Cidades, cujo objetivo consiste em diminuir as desigualdades sociais, organizando e democratizando o espaço urbano (Brasil, 2016a). Em alguma medida, a Agenda 21 menciona a importância da aproximação entre governos e população, convocados a incorporar um posicionamento responsável no que diz respeito ao meio ambiente. No documento consta:

8.7. Os Governos, em cooperação, quando apropriado, com as organizações internacionais, devem adotar uma estratégia nacional que tenha como meta o desenvolvimento sustentável e apoiada, inter alia, na implementação das decisões adotadas na Conferência, particularmente no que diz respeito à Agenda 21. Essa estratégia deve ser construída a partir das diferentes políticas e planos econômicos, sociais e ambientais adotados no país e em conformidade com eles. A experiência adquirida por meio das atividades de planejamento em curso, como os relatórios nacionais para a Conferência, as estratégias nacionais de conservação e os planos de ação para o meio ambiente, deve ser integralmente utilizada e incorporada a uma estratégia de desenvolvimento sustentável impulsionada pelo país. Seus objetivos devem assegurar um desenvolvimento econômico socialmente responsável e ao mesmo tempo proteger as bases de recursos e o meio ambiente, para benefício das gerações futuras (Brasil, 2016b).
As dificuldades nacionais para avançar em tal proposição são evidentes. Sobre isso, Rolnik e Klink salientam: "embora desde 2001 tenha sido aprovado um novo marco regulatório - o Estatuto da Cidade -, que, em tese, dotaria os municípios de maior poder sobre o processo de urbanização, as formas predominantes de regulação, parcelamento do solo e zoneamento - foram pouco modificadas" (Rolnik, \& Klink, 2011). Os autores ainda ressaltam: "o pacto político territorial que permitiria a implementação da função social da propriedade não ocorreu. O mesmo podemos afirmar em relação às instâncias participativas no campo do desenvolvimento urbano" (Rolnik, \& Klink, 2011).É precisamente nesse contexto que toma forma um problema decisivo para a Psicologia, comprometida com as temáticas social e ambiental: Como intervir de modo a promover a participação coletiva nos processos decisórios sobre o meio ambiente? Como atuar nas coletividades tendo como objetivos o engajamento e a mobilização face aos desafios ecológicos que se coloca? Trata-se de um problema complexo, uma vez que o engajamento e a participação têm por pressuposto a ação voluntária da população, sua escolha deliberada por se inserir no debate. E se, eventualmente, os coletivos adotarem uma postura passiva e fatalista (Guattari, 1997) diante da situação, transitando, assim, para a resignação perante o quadro caótico que ora se engendra nas cidades?

Para além da mera conscientização, estes questionamentos têm como horizonte comum o desejo coletivo. Tal desejo pode ser compreendido como um componente subjetivo de presença incontornável e inalienável no âmbito das mobilizações que expressam os anseios coletivos. Ocorre que o desejo, como componente de subjetivação engendrado no social (Guattari, \& Rolnik, 1996), pode estar ou não investido nos processos que incidem sobre a vida de todos. Pode, inclusive, se ausentar evidenciando os limites da participação social, manifestando-se pela baixa intensidade e pela indiferença para com o espaço público. Tal situação nos expõe a um cenário bastante delicado.

Sem adotar uma postura desqualificativa do documento aqui analisado, convém considerar que o mesmo traz essa problemática crucial do desejo que, no entanto, é tratado apenas de modo indireto. $\mathrm{O}$ desejo comparece implicitamente quando se aponta para a necessidade de engajamento e participação coletiva voluntária nas questões da preservação eco- 
lógica. Cabe salientar que, por vezes, tal mobilização ocorre em uma escala microssocial ou, como diria Godoy (2008), a partir de uma "ecologia menor" inscrita no cotidiano das relações sociais e que é, no mais das vezes, desconsiderada pelo aparato governamental, cuja prioridade é a análise macrossocial.

Possivelmente, este é um problema decisivo para os destinos da vida no planeta. A conservação do meio ambiente solicita transformações subjetivas e envolvimento populacional em escala mundial. É o que consideram Guattari e Rolnik quando assinalam: "Não se pode conceber resposta ao envenenamento da atmosfera e ao aquecimento do planeta, devidos ao efeito estufa, uma estabilização demográfica, sem uma mutação das mentalidades, sem a promoção de uma nova arte de viver em sociedade" (Guattari, \& Rolnik, 1996, p. 33).

É compreensível que a iniciativa de elencar objetivos e metas, assim como fixar prazos para o enfrentamento da crise ambiental em que nos encontramos não seja suficiente para desencadear os movimentos sociais e os processos de mobilização que uma mudança dessa magnitude requer. Para além daquilo a que denominamos conscientização, engajamento e participação, uma ruptura com a dinâmica acelerada da destruição ambiental só se concretiza à medida que se torna objeto de um investimento do desejo. Como considera Guattari e Rolnik:

O desejo permeia o campo social, tanto em práticas imediatas quanto em projetos muito ambiciosos. Por não querer me atrapalhar com definições complicadas, eu proporia denominar desejo a todas as formas de vontade de viver, de vontade de criar, de vontade de amar, de vontade de inventar outra sociedade, outra percepção do mundo, outros sistemas de valores (1996, p. 215).

Resistindo de antemão a todos os discursos que nos convocam a aceitar o intolerável da catástrofe ambiental, Guattari e Rolnik (1996) colocam em evidência a constatação de que a humanidade não é prisioneira de um movimento cego rumo à destruição. É necessário, no entanto, que se supere a passividade fatalista já instalada, admitindo a urgência da confrontação com os modos predatórios de ordenamento social capitalista, tal como comparece no fragmento que se segue:
É perfeitamente concebível que um outro tipo de sociedade se organize, a qual preserve processos de singularidade na ordem do desejo, sem que isso implique uma confusão total na escala da produção e da sociedade, sem que isso implique uma violência generalizada e uma incapacidade de a humanidade fazer a gestão da vida. É muito mais a produção de uma subjetividade capitalística - que desemboca em devastações incríveis a nível ecológico, social, no conjunto do planeta - que constitui um fato de desordem considerável, e que, aí sim, pode nos levar a catástrofes absolutamente definitivas (Guattari, \& Rolnik, 1996, p. 217).

Também não se trata de condicionar as imensas transformações sociais às quais a Agenda 21 nos convoca ao comparecimento de um componente supostamente excepcional que seria o desejo. Nas proposições dos autores, os processos desejantes não se dissociam dos acontecimentos históricos, caracterizando-se antes como constituintes dos mesmos. Cabe considerar que todos "os fenômenos importantes da atualidade envolvem dimensões de desejo e subjetividade" (Guattari, \& Rolnik, 1996, p. 28). Articular e tornar coextensivos os dois campos aqui explorados, aquele da definição de metas e objetivos proposto pela Agenda 21 e outro, do envolvimento afetivo e desejante das populações nas questões ecológicas é, seguramente, uma alternativa estratégica para a reversão das catástrofes ambientais anunciadas.

\section{Considerações finais}

Elaborar uma análise no âmbito da Psicologia acerca de um documento elaborado em contexto internacional foi estratégico para compreender o desafio no qual estamos imersos. De qualquer modo, ao final desta investigação, acumulamos condições conceituais e analíticas para responder, ou ao menos sustentar um debate, acerca da seguinte questão: Em que tipo de cidade desejamos viver e o que estamos fazendo para construí-la?

A sistemática adesão populacional a uma organização socioeconômica capitalista trouxe muitas conquistas e, indissociável delas, problemas complexos, tais como a desigualdade social, a depredação sistemática da natureza e a banalização da destruição ambiental. Neste estudo, destacamos os efeitos 
produzidos pela subjetividade capitalística que atravessa a vida urbana com seus desdobramentos de indiferença pela depredação e privatização do uso do espaço público. Acompanhamos as considerações de Harvey (2013b) para quem essa prática de construção coletiva dos novos modos de vida nas cidades não está dada. Ela demanda uma série de lutas, algumas delas já em curso, pela reapropriação do espaço urbano em nível afetivo, social ou ambiental.

Assim, uma análise sobre a relação entre homem e natureza no espaço urbano, empreendida no campo conceitual da Psicologia Social, a partir de fragmentos selecionados da Agenda 21, serviu para evidenciar um tipo de indiferença crescente, em escala populacional, para com as questões referentes ao meio ambiente. Em decorrência direta dessa constatação, tem-se o reconhecimento de que as lutas políticas e sociais incorporam componentes subjetivos vários, para além dos já tão assinalados processos de conscientização. À Psicologia Social cabe intervir decisivamente no enfrentamento dos desafios elencados, criando estratégias de sensibilização que atinjam os diferentes segmentos sociais afetados pela questão ambiental. Ela pode apresentar uma leitura crítica e conceitual por meio da qual as questões do desejo, assim como as da consciência, tenham espaço para serem apropriadas em escala populacional. Trata-se, em nosso entendimento, de uma economia política do desejo voltada para um planeta sustentável que potencialize a vida em suas diferentes formas.

Salientamos, nesta finalização, os limites encontrados para levar adiante a investigação, uma vez que a problemática evidenciada pelo documento analisado ainda carece de iniciativas significativas que atuem no sentido de colocá-lo em prática. Após esta análise teórica e documental, uma próxima etapa de investigação poderia ser concretizada no sentido de levantar as iniciativas nacionais que tiveram sucesso na implementação da Agenda 21. Daí a necessidade premente de dar continuidade à produção de conhecimento sobre os documentos gerados em conferências de âmbito nacional e internacional, adotando um enfoque crítico que priorize uma análise contextualizada das questões referentes ao meio ambiente e aos destinos da vida em nosso planeta. Consideramos que as dimensões do desejo, do afeto e das políticas de subjetivação inserem-se nesse contexto tornando ainda maior o desafio de reverter o atual estado de coisas.

\section{Referências}

Bertini, F. M. A. (2014). Mudanças urbanas e afetos: Estudo de uma cidade planejada (Tese de doutorado). Pontifícia Universidade Católica de São Paulo, São Paulo, SP, Brasil.

Brasil. Ministério das Cidades. (2016a). Página principal. Brasília, DF: o autor. Recuperado de: http:/ /www.cidades.gov.br/

Brasil. Ministério do Meio Ambiente. (2016b). Agenda 21. Brasília, DF: o autor. Recuperado de: http://www.mma. gov.br/responsabilidade-socioambiental/agenda-21/agenda-21-global

Burton, M. (2015). Economy and planet: A blind spot for community psychology? Universitas Psychologica, 14(4), 1339-1346. https://doi.org/10.11144/Javeriana.upsyl4-4.epbs

Castro, E. V. (2015). Metafísicas canibais: Elementos para uma antropologia pós-estrutural. São Paulo, SP: Ubu.

Foucault, M. (2014). Ditos e escritos X: Filosofia, diagnóstico do presente e verdade. Rio de Janeiro, RJ: Forense Universitária.

Godoy, A. (2008). A menor das ecologias. São Paulo, SP: Edusp.

Guattari, F. (1992). Caosmose: Um novo paradigma estético. São Paulo, SP: 34.

Guattari, F. (1997). As três ecologias. Campinas, SP: Papirus.

Guattari, F., \& Rolnik, S. (1996). Micropolítica: Cartografias do desejo. Petrópolis, RJ: Vozes.

Harvey, D. (2013b). A liberdade da cidade. In E. Maricato (Org.), Cidades rebeldes: Passe livre e as manifestações que tomaram as ruas do Brasil (pp. 27-34). São Paulo, SP: Boitempo.

Harvey, D. (2013a). Os limites do capital. São Paulo, SP: Boitempo.

Malheiros, T. F., Phlippi, A., Jr., \& Coutinho, S. M.V. (2008). Agenda 21 nacional e indicadores de desenvolvimento sustentável: Contexto brasileiro. Saúde e Sociedade, 17(1), p.7-20. https://doi.org/10.1590/S0104-12902008000100002 
Massumi, B. (2017) O que os animais nos ensinam sobre política. São Paulo, SP: N-1.

Meadows, D. L., Meadows, D. H., Randers, J. \& Behrens, W. W. (1972). Limites do crescimento - um relatório para o Projeto do Clube de Roma sobre o dilema da humanidade. São Paulo, SP: Perspectiva.

Misoczky, M. C., \& Böhm, S. (2012). Do desenvolvimento sustentável à economia verde: A constante e acelerada investida do capital sobre a natureza. Cadernos EBAPE.BR, 10(3), 546-568.

Paulista, G., Varvakis, G., \& Montibeller, G., Filho. (2008). Espaço emocional e indicadores de sustentabilidade. Ambiente \& Sociedade, 11(2), 185-200. https://doi.org/10.1590/S1414-753X2008000100013

Rolnik, R. (2013). Apresentação. In E. Maricato (Org.), Cidades rebeldes: Passe livre e as manifestações que tomaram as ruas do Brasil (pp. 1-4). São Paulo, SP: Boitempo.

Rolnik, R., \& Klink, J. (2011). Crescimento econômico e desenvolvimento urbano: Por que nossas cidades continuam precárias. Novos estudos CEBRAP, (89), 89-109.

Sassen, S. (2016). Expulsões: Brutalidade e complexidade na economia global. Rio de Janeiro, RJ: Paz e Terra.

Santos, M. (2012). Por uma economia política das cidades. São Paulo, SP: Edusp.

Stengers, I. (2015). No tempo das catástrofes: Resistir à barbárie que se aproxima. São Paulo, SP: Cosac Naif.

Veiga, J. E. (2006). Desenvolvimento sustentável: O desafio do século XXI. Rio de Janeiro, RJ: Garamond.

Vizeu, F., Meneghetti, F. K., \& Seifert, R. E. (2012). Por uma crítica ao conceito de desenvolvimento sustentável. Cadernos EBAPE.BR, 10(3), 569-583. https://doi.org/10.1590/S1679-39512012000300007

Žižek, S. (2017). Acontecimento: Uma viagem filosófica através de um conceito. Rio de Janeiro, RJ: Zahar.

\section{Paulo Roberto de Carvalho}

Doutor em Psicologia Clínica pela Pontifícia Universidade Católica de São Paulo (PUC/SP), São Paulo - SP. Brasil. Docente do Programa de Pós-graduação em Psicologia e do Departamento de Psicologia Social e Institucional da Universidade Estadual de Londrina, Londrina - PR. Brasil.

E-mail: paulor@uel.br

http://orcid.org/0000-0002-5732-5557

\section{Sonia Regina Vargas Mansano}

Doutora em Psicologia Clínica pela Pontifícia Universidade Católica de São Paulo (PUC/SP), São Paulo - SP. Brasil. Docente do Programa de Pós-graduação em Psicologia e do Departamento de Psicologia Social e Institucional da Universidade Estadual de Londrina, Londrina - PR. Brasil.

E-mail:mansano@uel.br

http://orcid.org/0000-0002-4406-8803

Endereço para correspondência:

Paulo Roberto de Carvalho

Universidade Estadual de Londrina, campus Universitário. Centro de Ciências Biológicas. Departamento de Psicologia Social e Institucional. Caixa Postal: 6001. CEP: 86051-990. Londrina - PR. Brasil.

Recebido 04/12/2017

Reformulado 26/06/2018

Aceito 10/07/2018

Received 12/04/2017

Reformulated 06/26/2018

Approved 07/10/2018 
Recibido 04/12/2017

Reformulado 26/06/2018

Aceptado 10/07/2018

Como citar: Carvalho, P.R e Mansano, S.R.V. (2019). Ecologia e Mobilização Social: um Desafio para a Psicologia. Psicologia: Ciência e Profissão, 39, 1-13. https://doi.org/10.1590/1982-3703003188690

How to cite: Carvalho, P.R e Mansano, S.R.V. Ecology and Social Mobilization: a Challenge for Psychology.

Psicologia: Ciência e Profissão, 39, 1-13. https://doi.org/10.1590/1982-3703003188690

Cómo citar: Carvalho, P.R e Mansano, S.R.V. Ecología y la Movilización Social: un Desafío para la Psicología.

Psicologia: Ciência e Profissão, 39, 1-13. https://doi.org/10.1590/1982-3703003188690 